\title{
SIMILARITY ANALYSIS AND SCALING CRITERIA FOR LWR'S UNDER SINGLE-PHASE AND TWO-PHASE NATURAL CIRCULATION
} by

M. Ishii and I. Kataoka

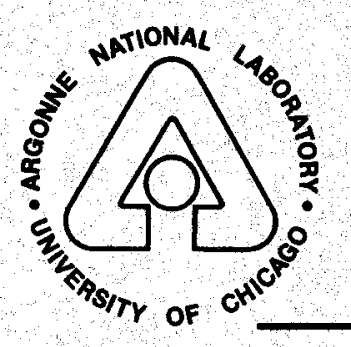

ARGONNE NATIONAL LABORATORY, ARGONNE, ILLINOIS

Prepared for the Office of Nuclear Regulatory Research U. S. NUCLEAR REGULATORY COMMISSION under Interagency Agreement DOE 40-550-75 


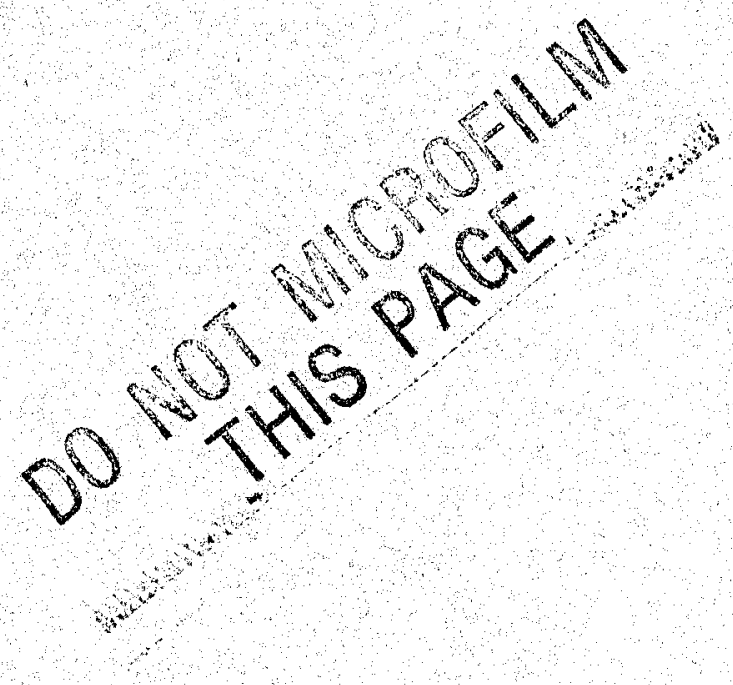

NOTICE

This report was prepared as an account of work sponsored by an agency of the United States Government. Neither the United States Government nor any agency thereof, or any of their employees, makes any warranty, expressed or implied, or assumes any legal liability or responsibility for any third party's use, or the results of such use, of any information, apparatus, product or process disclosed in this report, or represents that its use by such third party would not infringe privately owned rights.

\section{Available from}

GPO Sales Program

Division of Technical Information and Document Control

U. S. Nuclear Regulatory Commission

Washington, D.C. 20555

$$
\text { and }
$$

National Technical Information Service Springfield, Virginia 22161 


\section{DISCLAIMER}

This report was prepared as an account of work sponsored by an agency of the United States Government. Neither the United States Government nor any agency Thereof, nor any of their employees, makes any warranty, express or implied, or assumes any legal liability or responsibility for the accuracy, completeness, or usefulness of any information, apparatus, product, or process disclosed, or represents that its use would not infringe privately owned rights. Reference herein to any specific commercial product, process, or service by trade name, trademark, manufacturer, or otherwise does not necessarily constitute or imply its endorsement, recommendation, or favoring by the United States Government or any agency thereof. The views and opinions of authors expressed herein do not necessarily state or reflect those of the United States Government or any agency thereof. 


\section{DISCLAIMER}

Portions of this document may be illegible in electronic image products. Images are produced from the best available original document. 


\section{SIMILARITY ANALYSIS AND SCALING CRITERIA FOR LWR'S UNDER SINGLE-PHASE AND TWO-PHASE NATURAL CIRCULATION \\ by
M. Ishii and I. Kataoka*

Reactor Analysis and Safety Division

March 1983

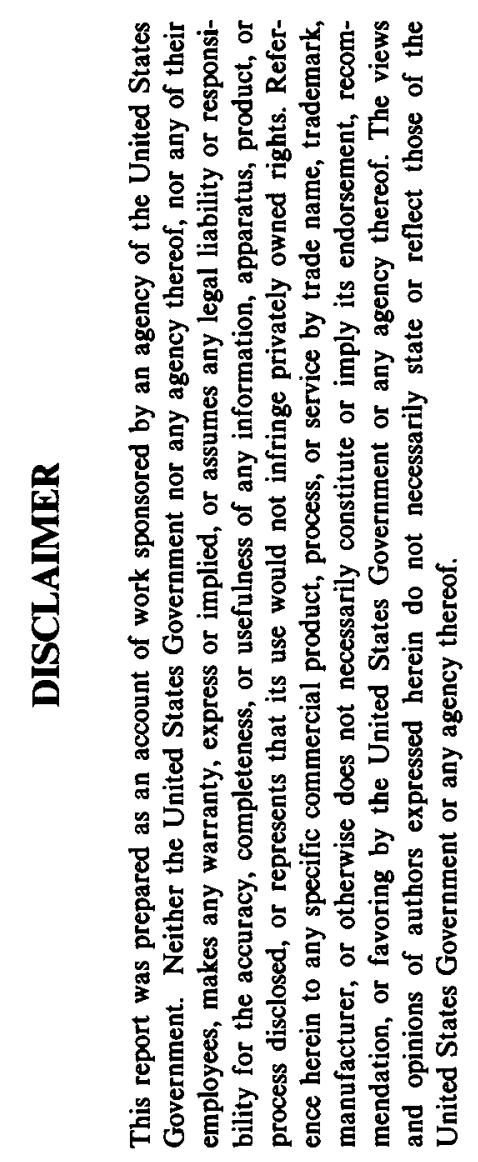

*Visiting scientist from Institute of Atomic Energy, Kyoto University, Japan. 
SIMILARITY ANALYSIS AND SCALING CRITERIA FOR LWR'S UNDER SINGLE-PHASE AND TWO-PHASE NATURAL CIRCULATION

by

M. Ishii and I. Kataoka

\begin{abstract}
Scaling criteria for a natural circulation loop under single phase and two-phase flow conditions have been derived. For a single phase case the continuity, integral momentum, and energy equations in one-dimensional area average forms have been used. From this, the geometrical similarity groups, friction number, Richardson number, characteristic time constant ratio, Biot number, and heat source number are obtained. The Biot number involves the heat transfer coefficient which may cause some difficulties in simulating the turbulent flow regime. For a two-phase flow case, the similarity groups obtained from a perturbation analysis based on the one-dimensional drift-flux model have been used. The physical significance of the phase change number, subcooling number, drift-flux number, friction number are discussed and conditions imposed by these groups are evaluated. In the two-phase flow case, the critical heat flux is one of the most important transients which should be simulated in a scale model. The above results are applied to the LOFT facility in case of a natural circulation simulation. Some preliminary conclusions on the feasibility of the facility have been obtained.
\end{abstract}

NRC FIN No.

Title

A2026

Phenomenological Modeling of Two-phase Flow in Water Reactor Safety Research 


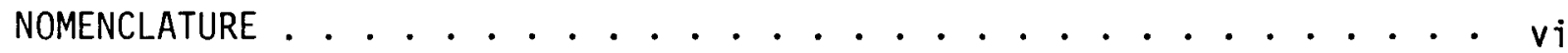

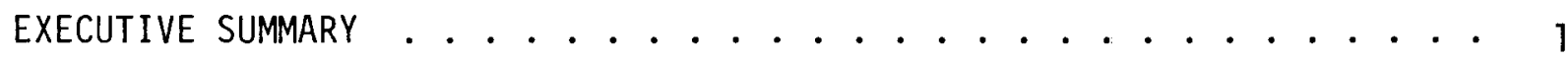

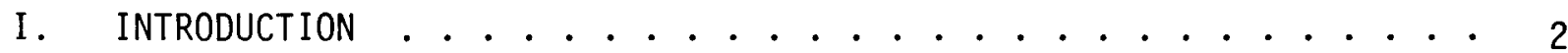

II. SINGLE PHASE SIMILARITY LAWS .............. 3

A. Similarity Parameters for Single Phase Natural Convection . . . 3

B. General Similarity Laws ............... 8

C. Scale Model with Same Fluid ............. 13

D. Sample Calculations (Real Time Scale)........ 16

III. TWO-PHASE SIMILARITY LAWS . . . . . . . . . . . 20

A. Basic Formulation for Two-phase Natural Circulation . . . . 20

B. Steady State Formulation for Two-phase Flow . . . . . . 24

C. Similarity Criteria for Two-phase Flow . . . . . . . 27

D. Scale Model with Same Fluid............. 29

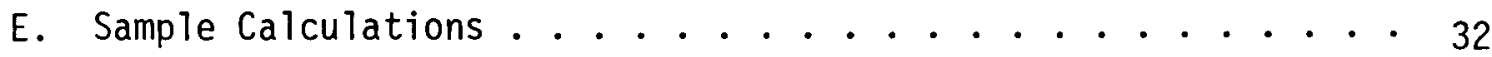

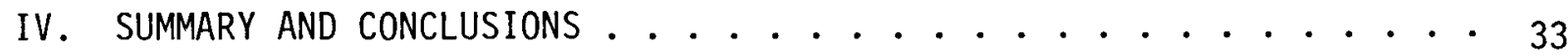

ACKNOWLEDGMENTS . . . . . . . . . . . . . . . 36

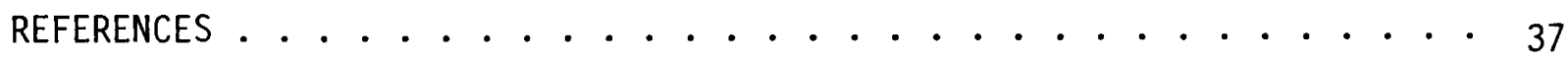




\section{LIST OF FIGURES}

No.

Title

Page

1 Schematics of Natural Circulation in LWR . . . . . . . . 4

2 Simplified LWR Geometry Relevant to Natural Circulation (Dimensions in $\mathrm{m}$ ) ................. 17

$3 \quad$ Simplified LOFT Facility Geometry Relevant to Natural Circulation (Dimensions in $\mathrm{m}$ ) ........... 18

TABLE

1 Basic Geometrical Parameters for PWR and LOFT Facility . . . 19 

NOMENCLATURE

Flow area

Wall cross sectional area

Non-dimensional area

Biot number

Fluid heat capacity

Solid heat capacity

Distribution parameter

Hydraulic diameter

Friction factor

Friction number

Void-quality relation

Gravity

Grashof number

Mass velocity

Heat transfer coefficient

Enthalpy of mixture

Total volumetric flux

Conductivity of liquid

Conductivity of solid

Orifice coefficient

Axial length

Length of hot fluid section

Non-dimensional length

Non boiling length (heated section)

Non boiling head (cooled section)

Nusselt number

Phase change number

Subcooling number

Froude number

Drift flux number

Density ratio

Friction number (two-phase)

Orifice number (two-phase)

critical heat flux number 

NOMENCLATURE (Cont'd)

$\mathrm{Pr} \quad$ Prandt1 number

Pressure

Heat generation in solid

Heat source number

Heat flux

Critical heat flux

Richardson number

Reynolds number

Stanton number

Time

Fluid temperature

Solid temperature

Saturation temperature

Characteristic time ratio

Velocity (1iquid)

Representative velocity

Liquid velocity

Vapor velocity

Mixture velocity

Non-dimensional velocity

Drift velocity

Vapor quality

Exit quality

transverse distance

Non-dimensional transverse distance

Axial distance

Non-dimensional axial distance

Greek Symbols

$\alpha \quad$ Void fraction

$\alpha_{e} \quad$ Exit void fraction

Solid thermal diffusivity

Therma 1 expansion coefficient

Vapor mass source

Conduction thickness 

NOMENCLATURE (Cont'd)

$\delta(z) \quad$ Delta function

Characteristic temperature rise

Latent heat

$\Delta \mathrm{H}_{\mathrm{fg}} \quad$ Subcooling

$\Delta p \quad$ Pressure drop

Density difference

Viscosity difference

Non-dimensional temperature

Viscosity of Tiquid

Wetted (heated) perimeter

Density of liquid

Density of solid

Surface tension

Non-dimensional time

\section{Subscripts}

$i$ th section

Reference constant (heated section)

Representative variable

Solid

Hot

Cold

Model to prototype ratio

Inlet

Exit

Mixture

Vapor

( ) Mode1

()$_{p}$ Prototype 


\section{EXECUTIVE SUMMARY}

Similarity laws and scaling criteria are quite important for designing, performing, and analyzing simulation experiments using a scale model. They are particularly important for studying phenomena which cannot be easily observed in a prototype model. Nuclear reactor transients and accidents fall into this category. It is obvious that full scale experiments will be too dangerous and costly, thus it is necessary to use scale models and simulation experiments.

In view of the above, scaling criteria for single phase and two-phase flow loops have been developed with special emphasis on a natural circulation mode. The similarity criteria have been obtained from conservation equations, boundary conditions, and geometry of a system. For a whole loop simulation it is very important to consider not only local conditions but also integral effects over an entire loop and components. Thus it becomes necessary to include integral balances in the similarity analysis.

For a single phase flow, the continuity, integral momentum, and energy equation in one-dimensional area averaged forms have been used. First, relevant scales for basic parameters are determined, then the similarity groups have been obtained from the conservation equations and boundary conditions. The heat transfer between the fluid and structure is included in the analysis by using the solid energy equation. From these, the geometrical similarity groups, friction number, Richardson number, characteristic time constant ratio, Biot number, and heat source number are obtained. The Biot number involves the heat transfer coefficient which may cause some difficulties in simulating the turbulent flow thermal boundary layer. However, overall similarity can be easily established by satsifying scaling critera developed under the study. In general, a real time simulation by a scale model is possible in the single phase region. It is noted that the simulation of a long, large pipe by a small scale model may encounter some difficulties if a prototype system does not have a reasonably large loss coefficient in addition to the wall frictional loss.

For a two-phase flow case, similarity gorups have been developed from a perturbation analysis based on the one-dimensional drift-flux model. The physical significance of the phase change number, subcooling number, driftflux number, friction number are discussed in detail and conditions imposed 
by these groups are evaluated. In two-phase flow case, the occurrence of the critical heat flux is one of the most important transients which should be simulated in a scale model. Simulation experiments using a scale model and same fluid under prototypic pressure and temperature conditions are one of the most important special cases. This is particularly so in nuclear reactor safety experiments. Therefore, this case is studied in detail and specific scaling criteria are developed. These new criteria have considerable practical importance in designing integrated or separate test facilities for nuclear reactor safety related experiments.

The above results are applied to the LOFT facilities in case of a natural circulation simulation. Some preliminary conclusions on the feasibility of the facility have been obtained. The results show that the real time simulation is only possible in case of a single phase flow. Simulations of twophase phenomena require a distortion of time scale. This is the single most important conclusion from the application of the present criteria to the scale model.

\section{INTRODUCTION}

The scaling laws for forced convection single phase flow have been well established and modeling using these criteria has long been an accepted practice. Similar reasons exist for the desire to model natural circulation single and two-phase flows. However, the similarity analysis for a natural circulation system is much more complicated due to the coupling of the driving force and heat transfer processes. The flow condition can only be determined by the integral effect of the thermo-hydraulic processes along the entire loop. Therefore, in order to develop meaningful similarity criteria, it is necessary to consider these integral effects through some forms of simplified solutions.

There are some publications on a simulation of a single phase natural circulation system. For example, Heisler and Singer [1] and Heisler [2] have analyzed the simulation of a liquid metal natural circulation system. The similarity analysis for a two-phase flow system has been carried out by Ishii and Zuber [3], Ishii and Jones [4], and Zuber [5] among others. The determination of scaling criteria for single phase flow is achieved through appropriate non-dimensionalization of the well established balance and constitutive 
equations. However, the same approach for two-phase flow encounters considerable difficulties due to the existing uncertainties in the basic formulation related to balance equations, two-phase flow correlations, and flow regime transition criteria.

The available methods to develop similarity criteria for two-phase flow systems have been reviewed by Ishii and Jones [4]. In the present analysis, the results based on the local conservation equations and ones based on the perturbation method are utilized. The extension of the similarity analysis to a natural circulation system is achieved by considering the scaling criteria from a small perturbation method and the steady state solution. For this purpose, the relatively well established drift-flux model and constitutive relations $[6,7]$ are used.

The above results are applied to the simulation of a natural circulation in pressurized light water reactors by the LOFT facility [8]. It is noted that the single phase and two-phase heat transfer under a natural circulation pattern is particularly important for LWR's. Accidents which lead to the decay heat removal by natural circulation have much higher probability than those of the severe accidents extensively studied recently. However, the breakdown of the natural circulation boiling which leads to dryout and burnout of heated surface in these conditions have significant consequences. A detailed study of the critical heat flux under these conditions has been carried out by Mishima and Ishii [9]. This result is used to analyze the requirements for the simulation of the critical heat flux phenomena in addition to the general thermo-hydraulic simulation.

\section{SINGLE PHASE SIMILARITY LAWS}

\section{A. Similarity Parameters for Single Phase Natural Convection}

The similarity criteria for a natural circulation system can be obtained from the integral effects of the local balance equations along the entire 10op. A typical system under consideration is shown in Fig. 1. This system consists of the heat source, heat sink, connecting piping system, and flow resistances such as orifices. For a single phase flow case, a method similar to that used by Heisler and Singer [1] and Heisler [2] for a liquid metal system is applied to develop similarity criteria. 


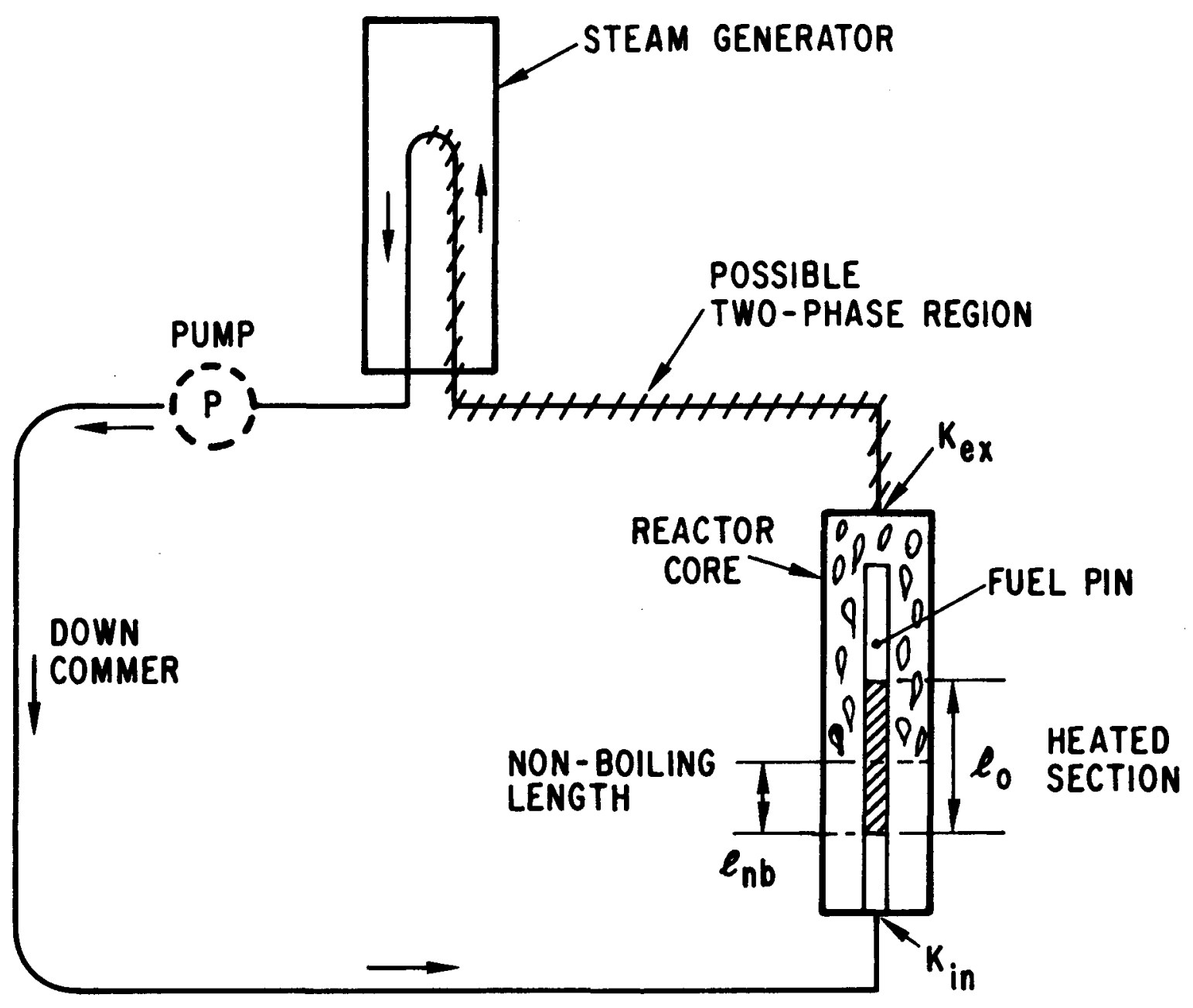

SINGLE PHASE REGION

HHHHH TWO-PHASE REGION

Fig. 1. Schematics of Natural Circulation in LWR 
In the following analysis, subscripts 0 and $r$ denote the reference constant value and representative variable of a system. The $i$ th component and solid are denoted by subscripts $i$ and $s$. Using the Boussinesq assumption for a single phase natural convection system, the fluid is considered incompressible, except in the gravitational term in the momentum equation. Then the conservation laws can be expressed by the following set of simplified balance equations based on a one-dimensional formulation.

Continuity Equation

$$
u_{i}=\frac{a_{0}}{a_{i}} u_{r}
$$

Integral Momentum Equation

$$
\rho \frac{d u_{r}}{d t} \sum_{i} \frac{a_{0}}{a_{i}} l_{i}=\beta g \rho \Delta T l_{h}-\frac{\rho u_{r}^{2}}{2} \sum_{i}\left(\frac{f \ell}{d}+k\right)_{i}\left(\frac{a_{0}}{a_{i}}\right)^{2} .
$$

Fluid Energy Equation for $i$ th Section

$$
\rho C_{p}\left\{\frac{\partial T}{\partial t}+u \frac{\partial T}{\partial z}\right\}=\frac{4 h}{d}\left(T_{s}-T\right) \text {. }
$$

Solid Energy Equation for $i$ th Section

$$
\rho_{s} C_{p s} \frac{\partial T_{s}}{\partial t}+k_{s} \nabla^{2} T_{s}-\dot{q}_{s}=0
$$

The boundary condition between the $i$ th section fluid and structure is given by

$$
-k_{s} \frac{\partial T_{s}}{\partial y}=h\left(T_{s}-T\right)
$$

In the above equations, $u_{r}$ is the representative velocity of the system corresponding to the velocity of the section having cross sectional area $a_{0}$. $l_{h}$ is the equivalent total length of the hot fluid sections. The above set of equations can be non-dimensionalized by introducing the following dimensionless parameters: 


$$
\begin{aligned}
& u_{i}=u_{i} / u_{0}, u_{r}=u_{r} / u_{0} \\
& L_{i}=e_{i} / l_{0}, L_{h}=\ell_{h} / l_{0}, z=z / l_{0} \\
& \tau=t u_{0} / l_{0} \\
& \theta=\Delta T / \Delta T_{0} \\
& A_{i}=a_{i} / a_{0} \\
& \nabla^{\star 2}=\delta^{2} \nabla^{2}, Y=y / \delta
\end{aligned}
$$

The dimensionless balance equations can be given by the following expressions.

Continuity Equation

$U_{i}=U_{r} / A_{i}$

Momentum Balance

$$
\frac{d U_{r}}{d \tau}\left(\sum_{i} \frac{L_{i}}{A_{i}}\right)=R\left(\theta_{h}{ }^{-\theta} c\right) L_{h}-\frac{U_{r}^{2}}{2} \sum_{i}\left(F_{i} \frac{1}{A_{i}^{2}}\right) .
$$

Fluid Energy Equation (ith Section)

$$
\frac{\partial \theta_{i}}{\partial \tau}+\frac{U_{r}}{A_{i}} \frac{\partial \theta_{i}}{\partial Z}=S t_{i}\left(\theta_{s i}{ }^{-\theta_{i}}\right) .
$$

Solid Energy Equation (ith Section)

$$
\frac{\partial \theta_{s i}}{\partial \tau}+T^{\star} \nabla_{i}^{\star 2} \cdot \theta_{s i}-Q_{s i}=0 .
$$

Fluid-Solid Boundary Condition (ith Section)

$$
\frac{\partial \theta_{s i}}{\partial Y_{i}}=B_{i}\left(\theta_{s i}{ }^{-\theta}{ }_{i}\right) \text {. }
$$


The similarity groups appeared in the above equations are defined below.

Richardson No. $\quad ; R \equiv \frac{g B \Delta T_{0} l_{0}}{u_{0}^{2}}=\frac{\text { Buoyancy }}{\text { Inertia Force }}$

Friction No. $\quad ; F_{i} \equiv\left(\frac{f \ell}{d}+k\right)_{i}=\frac{\text { Friction }}{\text { Inertia Force }}$

Modified Stanton No.; $S t_{i} \equiv\left(\frac{4 h e_{0}}{\rho C_{p} u_{0} d}\right)_{i}=\frac{\text { Wall Convection }}{\text { Axial Convection }}$

Time Ratio No. $\quad ; T_{i}^{\star} \equiv\left(\frac{\alpha_{s}}{\delta^{2}} \frac{\ell_{0}}{u_{0}}\right)_{i}=\frac{\text { Transport Time }}{\text { Conduction Time }}$

Biot No. $\quad ; B_{i} \equiv\left(\frac{h \delta}{k_{s}}\right)_{i}=\frac{\text { Wall Convection }}{\text { Conduction }}$

Heat Source No. $\quad ; Q_{s i} \equiv\left(\frac{\dot{q}_{s} \ell_{0}}{\rho_{s} C_{p s} u_{0}^{\Delta T} T_{0}}\right)_{i}=\frac{\text { Heat Source }}{\text { Axial Energy Change }}$

In addition to the above defined physical similarity groups, several geometrical similarity groups are obtained. These are;

$$
\text { Axial Scale } ; L_{i}=l_{i} / l_{0} \quad\left(L_{h}=l_{h} / l_{0}\right)
$$

Flow Area Scale; $A_{i}=a_{i} / a_{0}$

It is noted here that the hydraulic diameter $d_{i}$ and the conduction depth $\delta_{i}$ are defined by

$$
d_{i}=4 a_{i} / \xi_{i}
$$

and

$$
\delta_{i}=a_{s i} / \xi_{i}
$$


where $a_{i}, a_{s i}$, and $\xi_{j}$ are the flow area, solid cross sectional area, and wetted perimeter of $i$ th section, respectively. Hence, $d_{i}$ and $\delta_{j}$ are related by

$$
d_{i}=4 \delta_{i}\left(\frac{a}{a_{s}}\right)_{i}
$$

In the above development, the reference scales for the velocity and temperature change have been used. The simplest way to obtain these scales are to use the steady state solutions. By taking the heated section as a representative section, one can obtain the following solution for temperature rise.

$$
\Delta T_{0}=\frac{\dot{q}_{0} l_{0}}{\rho C_{p} u_{0}}\left(\frac{a_{s o}}{a_{0}}\right)
$$

where subscript o denotes the heated section. Substituting the above expression into the steady' state momentum integral equation, the solution for the velocity becomes

$$
u_{0}=\left\{\frac{\beta\left(\frac{\dot{\mathrm{q}}_{0} \ell_{0}}{\rho C_{p}}\right) e_{h}\left(\frac{a_{\text {so }}}{a_{0}}\right)}{\frac{1}{2 g} \sum_{i}\left(F_{i} / A_{j}^{2}\right)}\right\}^{1 / 3} .
$$

\section{B. General Similarity Laws}

The similarity criteria between two different systems can be obtained from a detailed consideration of the similarity groups developed above together with necessary constitutive relations. In the following analysis, subcript $R$ denotes the ratio between the model and prototype. Thus

$$
\psi_{R} \equiv \frac{\psi_{m}}{\psi_{p}}=\frac{\psi \text { for model }}{\psi \text { for prototype }} .
$$

In general, the solid materials need not be the same between the model and prototype. However, for simplicity the use of the same materials for structures is assumed in the present analysis. This implies that 


$$
\rho_{s R}=C_{p S R}=k_{s R}=\alpha_{s R}=1 .
$$

The most fundamental requirement for the similarity is concerned with the geometrical similarity criteria. It is evident from the continuity relation that for a complete kinematic similarity the geometrical similarity for the flow area

$$
A_{i R}=\frac{\left(a_{j} / a_{0}\right)_{m}}{\left(a_{i} / a_{0}\right)_{p}}=1
$$

should be satisfied. On the other hand, from the dynamic similarity, it is necessary that

$$
\begin{aligned}
& \left(\sum_{i} L_{i} / A_{i}\right)_{R}=1 \\
& L_{h R}=-1
\end{aligned}
$$

These are somewhat weaker restrictions than the complete axial geometrical similarity given by

$$
L_{i R}=\frac{\left(e_{i} / l_{0}\right)_{m}}{\left(l_{i} / l_{o}\right)_{p}}=1 .
$$

However, for simplicity both the transverse area and axial length similarities are assumed at least where the energy transfer is important.

From the dynamical similarity condition one obtains that

$$
\left(\sum_{i} F_{i} / A_{i}^{2}\right)_{R}=1 \text {. }
$$

This requirement can be easily satisfied by using appropriate orifices, thus this restriction on the friction number is assumed to be satisfied unconditionally.

From the steady state condition given by Eqs. (18) to (25), the ratio of the reference velocities becomes 


$$
u_{O R}=\frac{u_{O M}}{u_{O p}}=\left\{\dot{q}_{O R}\left(\frac{\beta}{\rho C_{p}}\right)_{R} \frac{\delta_{O R}}{d_{O R}} e_{O R}^{2}\right\}^{1 / 3}
$$

where $\dot{q}_{o R}=\dot{q}_{o m} / \dot{q}_{o p}$ and $\ell_{R}=\ell_{o m} / \ell_{o p}$. Thus the temperature rise ratio is given by

$$
\Delta T_{o R}=\frac{\Delta T_{o m}}{\Delta T_{o p}}=\dot{q}_{O R}\left(\frac{1}{\rho C_{p}}\right)_{R} \frac{l_{O R}}{u_{o R}} \frac{{ }_{o R}}{d_{o R}} .
$$

By substituting Eq. (27) into the definition of the Richardson number, it can be shown that $R_{R}=1$ is equivalent to Eq. (26). Therefore, the correct scaling of velocity satisfies the Richardson number requirement automaticaliy. Then

$$
R_{R}=1 \text { equivalent to Eq. (26) . }
$$

On the other hand, the energy similarity conditions require that

$$
\begin{aligned}
& S t_{i R}=1 \\
& T_{i R}^{\star}=1 \\
& B_{i R}=1 \\
& Q_{S O R}=1
\end{aligned}
$$

It is noted here that the Stanton number and Biot number involve a heat transfer coefficient. Thus a form of the constitutive relation for $h$ becomes important. Under the conditions of

$$
\left\{\begin{array}{l}
\text { same solid materials, Eq. (20), } \\
\text { transverse flow area similarity, Eq. (22), and } \\
\text { axial length similarity, Eq. (24), }
\end{array}\right.
$$

the above energy similarity conditions reduce to

$$
T_{i R}^{\star}=e_{R} /\left(u_{R} \delta_{i R}^{2}\right)=1
$$




$$
\begin{aligned}
& B_{i R}=h_{R} \delta_{i R}=1 . \\
& Q_{S O R}=\left(\rho C_{p}\right)_{R} \frac{d_{O R}}{\delta_{O R}}=1 .
\end{aligned}
$$

For the last relation, the velocity scaling criteria, Eq. (26), and geometrical relation given by Eq. (16) have also been used. An important point is that the Stanton number requirement is satisfied automatically if the above three similarity criteria can be achieved.

Physically the time ratio scales the speed of transport processes in fluid and solid. The Biot number is the ratio of the thermal conductances in fluid and solid. Thus it is the scale for the boundary layer temperature drop and thermal gradient in solid. The heat source number is important for the temperature in solid and for the overall energy level of the system. The Stanton and Biot numbers are related to the boundary condition at the fluidsolid interface. Thus they contain a heat transfer coefficient. Under a natural circulation condition, relatively slow transients are anticipated. For these cases, the similarity requirement from these two numbers mainly contribute to the simulation of the temperature drop in the boundary layer and the interfacial temperature.

The requirements from the time constant ratio and heat source number lead to additional geometrical restrictions. Thus the conduction depth ( 2 wall thickness) should be

$$
\delta_{i R}=\delta_{R}=\sqrt{\frac{l_{R}}{u_{R}}}
$$

whereas the hydraulic diameter should be

$$
d_{o R}=d_{i R}=d_{R}=\frac{\delta_{R}}{\left(\rho C_{p}\right)_{R}}=\frac{1}{\left(\rho C_{p}\right)_{R}} \sqrt{\frac{l_{R}}{u_{R}}} .
$$

Furthermore, the Biot number similarity requires

$$
h_{i R}=h_{R}=\sqrt{\frac{u_{R}}{\ell_{R}}} .
$$


In contrast to the design parameters such as $\delta_{i}$ and $d_{j}$, the heat transfer coefficient cannot be determined independent of a flow field and fluid properties. Thus Eq. (35) imposes an additional constraint on the flow field.

In general the heat transfer coefficient depends on the fluid properties and flow conditions. It is customary to represent a correlation for $h$ in terms of the Nusselt number defined by

$$
\mathrm{Nu} \equiv \frac{\mathrm{hd}}{\mathrm{k}}
$$

where $d$ and $k$ are the hydraulic diameter and fluid conductivity. There are a number of correlations for $\mathrm{Nu}$ for a flow in a relatively long tube, however, the following three correlations typically represent the three important groups

$$
\left\{\begin{array}{ll}
\text { Laminar Flow (q given) } & \mathrm{Nu}=4.36 \\
\begin{array}{l}
\text { Turbulent Flow } \\
(1<\mathrm{Pr}<20)
\end{array} & \mathrm{Nu}=0.0155 \mathrm{Re}^{0.83} \mathrm{Pr}^{0.5} \\
\begin{array}{l}
\text { Liquid Metals } \\
(\mathrm{Pr}<0.1)
\end{array} & \mathrm{Nu}=4.82+0.0185(\operatorname{RePr})^{0.83}
\end{array} .\right.
$$

This shows that the Nusselt number depends on the Reynolds number and fluid properties.

On the other hand, in a free convection range, Nu depends on the length of a heated surface and the Grashof number defined by

$$
G r \equiv \frac{g B\left(T_{S}-T\right) e^{3}}{(\mu / \rho)^{2}}
$$

Then for a wide range of $\mathrm{Gr}$, the Nusselt number may be correlated by

$$
\mathrm{Nu}=0.3(\mathrm{GrPr})^{0.3}\left(\frac{\mathrm{d}}{\ell}\right)
$$

These different constitutive relations for $h$ indicate that the similarity requirements from the Stanton and Biot numbers are not easy to meet, 
particularly in the case of a fluid to fluid simulation. The correlation for forced convection flow given by Eq. (37) shows that it is desirable to use a fluid with a similar Prandtl number.

In a laminar flow range, the heat transfer correlation gives

$$
h_{R}=\frac{k_{R}}{d_{R}} \text {, }
$$

whereas for turbulent flow of fluid such as water

$$
n_{R}=\frac{k_{R}}{d_{R}}\left(\frac{\rho_{R} u_{R} d_{R}}{\mu_{R}}\right)^{0.83} \operatorname{Pr}_{R} .
$$

It is evident that Eqs. (40) and (41) impose quite different constraints on operational and design parameters with respect to Eq. (35). Furthermore, Eqs. (34), (35), and (41) require that the ratio of the Reynolds number to be close to one. For a scale model this may result in higher model velocity and very high model power. Because of this, the similarity condition based on the Biot or Stanton number should be carefully evaluated.

\section{Scale Model with Same Fluid}

A special case of a scale model with the same fluid is now examined. For this case all the property ratio groups can be set as unity. Thus

$$
\rho_{R}=\left(\frac{\beta}{\rho C_{p}}\right)_{R}=\left(\rho C_{p}\right)_{R}=k_{R}=\mu_{R}=P r_{R}=1 \text {. }
$$

Then the similarity laws developed above reduce to the following equations.

Reference Velocity Ratio

$$
u_{R}=\left\{\dot{q}_{O R} \frac{\delta_{R}}{d_{R}} \ell_{R}^{2}\right\}^{1 / 3} .
$$

Wa11 Conduction Depth Ratio

$$
\delta_{i R}=\delta_{R}=\sqrt{\frac{l_{R}}{u_{R}}} \text {. }
$$


Hydraulic Diameter Ratio

$d_{i R}=d_{R}=\sqrt{\frac{l_{R}}{u_{R}}}$.

Biot Number Similarity

$h_{R}=\sqrt{\frac{u_{R}}{l_{R}}}$.

Heat Transfer Laws

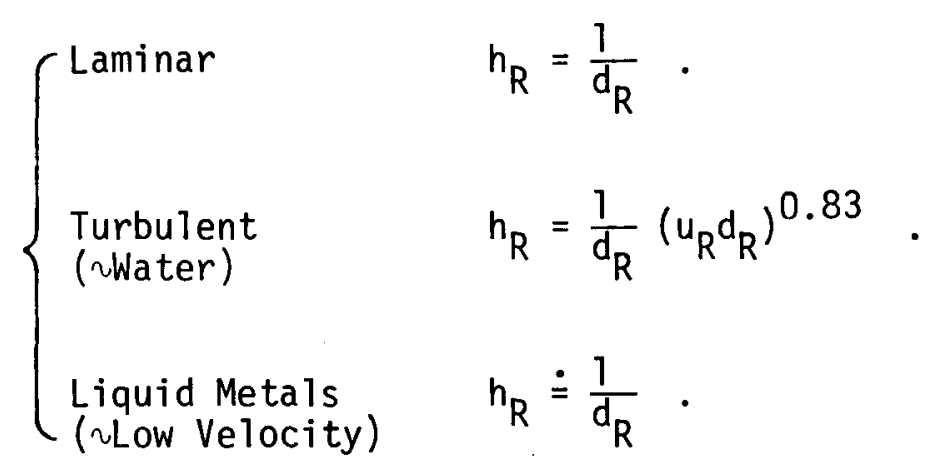

The Biot and Stanton number similarity conditions with the constitutive laws for the heat transfer coefficient mainly simulate the boundary layer temperature drop. When the heat transfer mechanism is not completely simulated, the system would adjust to a different temperature drop in the boundary layer. However, the overall flow and energy distribution will not be strongly affected in slow transients typical of a natural circulation system. The violation of the Biot or Stanton number similarity within the liquid flow condition should not cause a major problem except at very rapid power transients.

In view of the above, the first three conditions are of prime importance. The substitution of Eq. (44) and (45) gives

$$
u_{R}=\left(\dot{q}_{O R} \ell_{R}^{2}\right)^{1 / 3} \text {. }
$$

Hence

$$
\delta_{R}=d_{R}=\left(e_{R} / \dot{q}_{O R}\right)^{1 / 6} .
$$


From Eq. (16), this implies that

$$
\left(\frac{a}{a_{S}}\right)_{R}=1 \text {. }
$$

In addition to these conditions, the friction number similarity and geometrical similarity conditions should be satisfied. Thus

$$
\left[\sum_{i}\left(\frac{f \ell}{d}+k\right)\left(\frac{a_{0}}{a_{i}}\right)^{2}\right]_{R}=1
$$

and

$$
\left(\frac{l_{i}}{l_{0}}\right)_{R}=1,\left(\frac{a_{i}}{a_{0}}\right)_{R}=1 .
$$

The last geometrical similarity condition can be relaxed depending on the degree of similarity required. For example, the transverse area condition is important only where the heat transfer is significant because the velocity simulation in adiabatic sections is not important. In terms of the axial length similarity condition, it is important that Eq. (54) is satisfied in the hot leg section such that the driving head is well simulated. When Eq. (54) is partially violated, it is very important that Eq. (23) is satisfied such that the fluid transient time over the entire loop is correctly simulated. Hence

$$
\begin{aligned}
& \left(\sum_{i} L_{i} / A_{i}\right) R=1 \\
& L_{h R}=1
\end{aligned}
$$

In view of Eqs. (46) to (49), it becomes clear that a laminar flow or liquid metal flow at moderate Reynolds number can automatically satisfy the similarity criteria for solid-liquid boundary conditions, i.e., the Biot and Stanton number criteria. On the other hand, for a turbulent flow of water, it is almost impossible to satisfy them in a scale model due to the very much increased power demand in a model. 
A scale model can be designed by first determining the size of the model or $\ell_{R}$. This factor and the available power determine the velocity scale from Eq. (50). It is important to note that the time scale will be shifted by the factor

$$
t_{R}=\frac{l_{R}}{u_{R}}
$$

Therefore, for a real time simulation an additional condition of

$$
t_{R} \simeq 1 \text { or } \frac{\ell_{R}}{u_{R}} \simeq 1
$$

should be imposed. In this case, the power level can be uniquely determined by

$$
\dot{q}_{O R}=l_{R}
$$

Then one obtains

$$
\delta_{R}=d_{R}=1 \text {. }
$$

\section{Sample Calculations (Real Time Scale)}

As an example, a simulation of natural circulation flow in a typical light water reactor by the LOFT facility is considered. The representative geometry of PWR relevant to the natural circulation study is shown in Fig. 2 and that of LOFT facility [8] in Fig. 3. Here the PWR geometry is that of CE System 80. Some of the important design parameters are listed in Table I.

In view of the elevation $A F$ and $A B$, the axial length ratio $\ell_{R}$ is in the range of

$$
l_{R}=0.4 \sim 0.44 \text {. }
$$

For a real time simulation, the velocity should be reduced by the same factor as given by Eq. (57). Then 


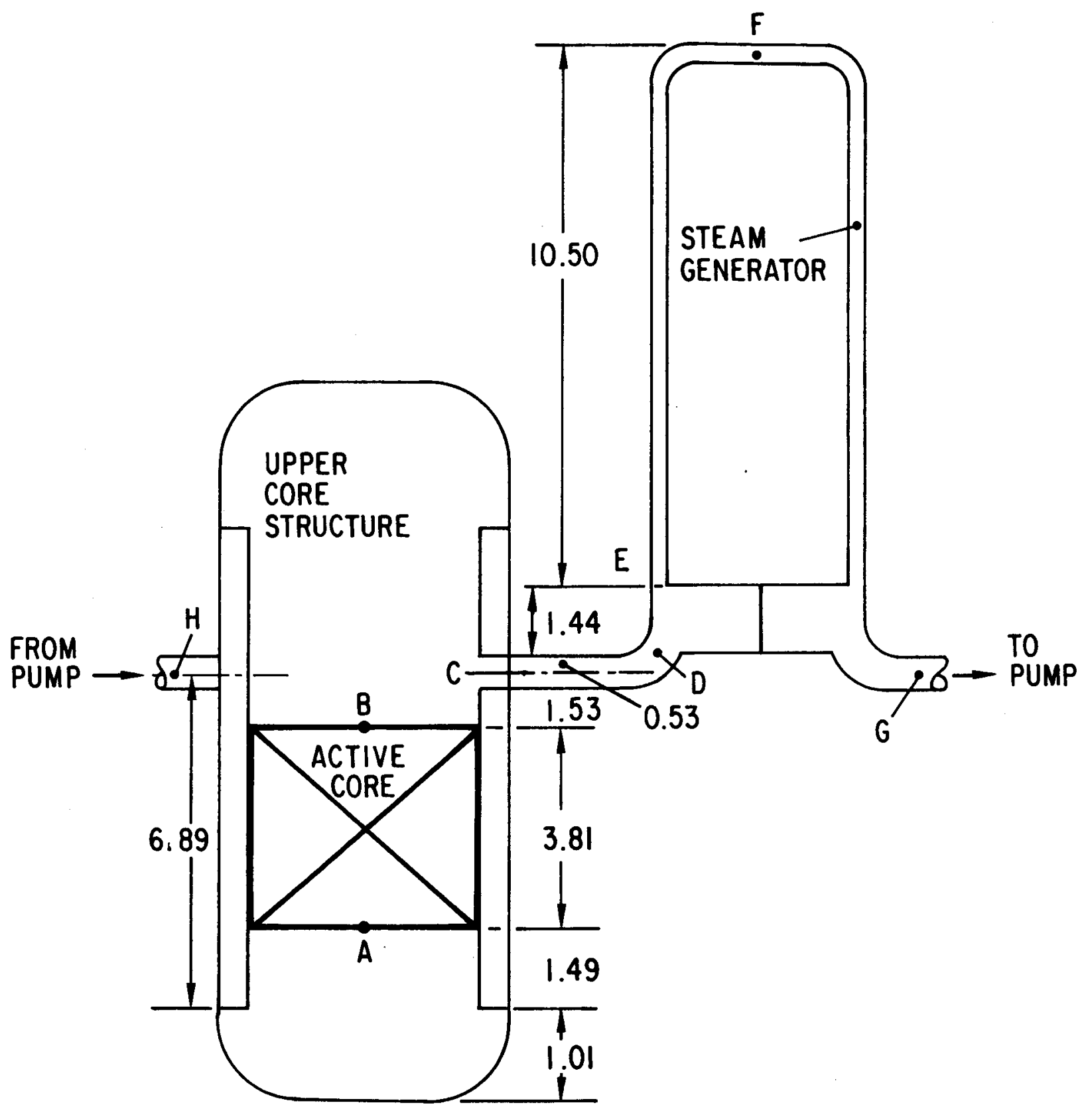

Fig. 2. Simplified LWR Geometry Relevant to Natural Circulation (Dimensions in $\mathrm{m}$ ) 


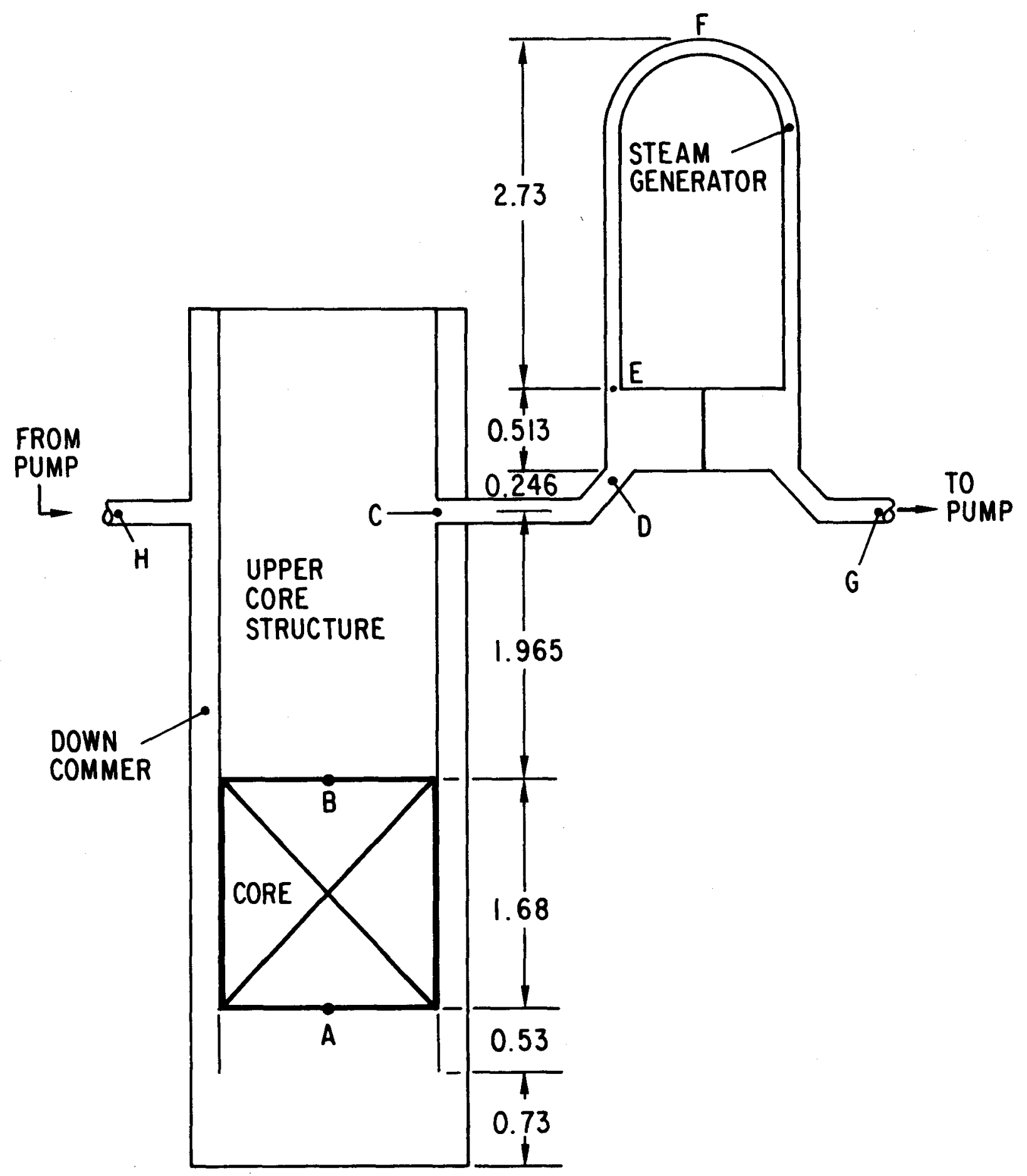

Fig. 3. Simplified LOFT Facility Geometry Relevant to Natural Circulation (Dimensions in $\mathrm{m}$ ) 
Table I. Basic Geometrical Parameters for PWR and LOFT Facility [8]

\begin{tabular}{|c|c|c|}
\hline$\underbrace{\text { System }}_{\text {Item }}$ & PWR & LOFT \\
\hline $\begin{aligned} & \text { Fuel Rod } \text { O.D., cm } \\
& \text { Length }(A B), \mathrm{cm} \\
& \text { Pitch, }\end{aligned}$ & $\begin{array}{l}0.97 \\
381 \\
7.29\end{array}$ & $\begin{array}{l}1.07 \\
168 \\
1.43\end{array}$ \\
\hline Hydraulic Diameter, $\mathrm{cm}$ & 1.2 & 1.363 \\
\hline No. of Rod & $\sim 55000$ & 1300 \\
\hline Elevation $B C, \mathrm{~cm}$ & 158 & 196.5 \\
\hline Elevation $C E, \mathrm{~cm}$ & 197 & 75.9 \\
\hline Elevation $\mathrm{EF}, \mathrm{cm}$ & 1050 & 273 \\
\hline SG Tube I.D., cm & 1.69 & 1.02 \\
\hline Wall Thickness, cm & 0.107 & 0.124 \\
\hline No. of Tube & $\sim 71000$ & 1845 \\
\hline
\end{tabular}




$$
\begin{aligned}
& u_{R}=0.4 \sim 0.44 \\
& q_{R}=0.4 \sim 0.44
\end{aligned}
$$

On the other hand, the hydraulic diameter and the conduction depth in the important heat transfer sections, i.e., the core and steam generator, should satisfy Eq. (59). From Table I it is clear that these conditions are satisfied. Hence, the single phase natural circulation can be easily simulated by the LOFT facility by installing appropriate offices and using proper length pipes in a horizontal section. In case of a turbulent flow, the boundary layer temperature drop cannot be simulated well due to unrealistic demand on the necessary power in the model. However, it is considered that this discrepancy may have little effect on the overall similarity of the systems.

Another major difference is the relative length of the steam generator tubes. The length ratio here is only 0.26 . Thus the axial length in the cooling region is much shorter in the model in relation to other sections. This may be a problem in case of rapidly changing power.

\section{TWO-PHASE SIMILARITY LAWS}

\section{A. Basic Formulation for Two-phase Natural Circulation}

The similarity parameters for a natural circulation system under a twophase condition can be obtained from the integral effects of the local twophase flow balance equations along the entire loop. Under a natural circulation condition, the majority of transients are expected to be relatively slow. Furthermore, for developing system similarity laws, the response of the whole mixture is important rather than the detailed responses of each phase and phase interactions

The basic concept of the drift flux model is to consider the motion and energy of mixture as a whole, rather than those of two phases separately. However, the drift flux model requires some additional constitutive assumptions on the phase interactions $[7,10,11]$. For the derivation of system similarity criteria under a natural circulation condition, the drift-flux model is appropriate $[3,4,12]$. This is because the drift-flux model can properly describe the mixture-structure interactions over a wide range of flow conditions. The overall similarity of two different systems in terms of mixture properties can be analyzed effectively by using the drift-flux model. 
The similarity criteria based on the drift flux model have been developed by Ishii and Zuber [3] and Ishii and Jones [4]. Two different methods have been used. The first method is based on the one-dimensional drift-flux model by choosing proper scales for various parameters. Since it is obtained from the differential equations, it has the characteristics of local scales. The second method is based on the small perturbation technique and consideration of the whole system responses. The local responses of main variables are obtained by solving the differential equations, then the integral effects are found. The resulting transfer functions are nondimensionalized. From these, the governing similarity parameters are obtained [3].

The first method based on the balance equations of the drift-flux model is useful in evaluating the relative importance of various physical effects and mechanisms existing in the system. However, there are certain shortcomings in this method when it is applied to a system similarity analysis. In developing the similarity criteria, the most important aspect is to choose proper scales for various variables. However, this may not always be simple or easy, because in a natural circulation system the variables change over wide ranges. Therefore, the scaling parameters obtained from this method are more locally oriented than system oriented.

The second method requires that the field and constitutive equations are firmly established and that the solutions to the small perturbations can be obtained analytically for the system under consideration. When these conditions are met, it gives quite useful similarity laws. In what follows, the combination of the results from the above two methods will be used to develop practical similarity criteria for a natural circulation system.

The drift-flux model obtained from the temporal and area averaging $[6,7$, 10] is given below.

Mixture Continuity Equation

$$
\frac{\partial \rho_{m}}{\partial t}+\frac{\partial}{\partial z}\left(\rho_{m} u_{m}\right)=0
$$

Continuity Equation for Vapor

$$
\frac{\partial \alpha \rho g}{\partial t}+\frac{\partial}{\partial z}\left(\alpha \rho_{g} u_{m}\right)=\Gamma_{g}-\frac{\partial}{\partial z}\left(\frac{\alpha g^{\rho}}{\rho_{m}} v_{g j}\right)
$$


Mixture Momentum Equation

$$
\begin{aligned}
\frac{\partial \rho_{m} u_{m}}{\partial t} & +\frac{\partial}{\partial z}\left(\rho_{m} u_{m}^{2}\right)=-\frac{\partial p_{m}}{\partial z}-\rho_{m} g-\frac{\partial}{\partial z}\left[\frac{\alpha \rho g}{(1-\alpha) \rho_{m}} v_{g j}^{2}\right] \\
& -\left[\frac{f m}{2 D}+k \delta\left(z-z_{j}\right)\right] \rho_{m} u_{m}\left|u_{m}\right| .
\end{aligned}
$$

Mixture Enthalpy Energy Equation (ith Section)

$$
\frac{\partial \rho_{m}{ }^{H}}{\partial t}+\frac{\partial}{\partial z}\left(\rho_{m} u_{m} H_{m}\right)=\frac{4 h_{m}}{d}\left(T_{s}-T_{s a t}\right)-\frac{\partial}{\partial z}\left[\frac{\alpha \rho_{g}{ }^{\rho}}{\rho_{m}} \Delta H_{f g} V_{g j}\right] \text {. }
$$

Solid Energy Equation (ith Section)

$$
\rho_{s} C_{p s} \frac{\partial T}{\partial t}+k_{s} \nabla^{2} T_{s}-\dot{q}_{s}=0
$$

Solid-Fluid Boundary Condition (ith Section)

$$
-k_{s} \frac{\partial T_{s}}{\partial y}=h_{m}\left(T_{s}-T_{s a t}\right)
$$

Here $v_{g j}$ is the drift velocity given by $v_{g j}=(1-\alpha)\left(u_{g}-u_{f}\right)$. The mixture friction factor and heat transfer coefficient are denoted by $f_{m}$ and $h_{m}$, respectively. The constitutive relations for the drift velocity, $V_{g j}$, and the vapor source term $\Gamma_{g}$ should be specified in the above formulation. Under the thermal equilibrium condition, it can be shown [3] that

$$
\Gamma_{g}=\frac{4 h_{m}\left(T_{s}-T_{s a t}\right)}{d \Delta H_{f g}}
$$

For water at relatively high pressure and under natural circulation conditions, the assumption of the thermal equilibrium is reasonable. The representative constitutive equation [7] for the drift velocity is given by

$$
v_{g j}=0.2\left(1-\sqrt{\rho_{g} / \rho}\right) j+1.4\left(\frac{\sigma g \Delta \rho}{\rho^{2}}\right)^{1 / 4}
$$


where the total flux $j$ is given by

$$
j=u_{m}+\frac{\alpha \Delta \rho}{\rho_{m}} v_{g j}
$$

The relative motion between phases can be specified by a number of different forms. For example, the classical void-quality correlation which gives

$$
\alpha=f(x)
$$

is mathematically equivalent to Eq. (69).

The heat transfer coefficient can be given by the standard correlations $[13,14]$. The boiling heat transfer is rather efficient, and the value of $h_{m}$ is generally very high. In normal conditions the wall superheat, $T_{s}-T_{\text {sat }}$ is relatively small. However, the occurrence of the critical heat flux (CHF) is significant, because the heat transfer coefficient is drastically reduced at CHF. Therefore, in two-phase flow the simulation of the CHF condition is much more important than that of the thermal boundary layer. The occurrence of $\mathrm{CHF}$ can be considered as a flow regime transition due to a change in heat transfer mechanisms.

In view of the above, the conduction in solid may be decoupled from the fluid convection for the purpose of the similarity analysis. Thus the boundary condition, Eq. (67), may be changed to

$$
T_{S} \doteq T_{\text {sat }} \text { (at solid-fluid boundary) }
$$

which is applicable from the boiling inception point to the CHF point.

The CHF condition at low flow has been reviewed by Leung [15], Katto [16], and Mishima and Ishii [9]. The modified Zuber correlation [17] for low flow is given by

$$
q_{c}^{\prime \prime}=0.14(1-\alpha) \rho g{ }^{\Delta H_{f g}}\left(\frac{\sigma g \Delta \rho}{\rho_{g}^{2}}\right)^{1 / 4} .
$$

Based on the limited data on blowdown experiments it is recommended [15] for the mass velocity range of -24 to $10 \mathrm{~g} / \mathrm{cm}^{2} \mathrm{sec}$. It is evident that this correlation is based on a pool boiling CHF mechanism. Thus it may apply only for transients involving flow reversal. 
Katto's correlation [16] for low flow is given by

$$
q_{C}^{\prime \prime}=\frac{1}{4} \Delta H_{f g} G \frac{d_{0}}{l_{0}}\left[\left(\frac{\sigma \rho}{G^{2} l_{0}}\right)^{0.043}+\frac{\Delta H_{\text {sub }}}{\Delta H_{f g}}\right]
$$

which implies that the critical quality is $x_{c}=\left(\sigma \rho / G^{2} l_{0}\right)^{0.043}$. Here $G$ and $\Delta \mathrm{H}_{\text {sub }}$ are the mass velocity and inlet subcooling. The typical value of $x_{c}$ is $0.5-0.8$, thus the underlining mechanism should be the annular flow film dryout. This correlation can be applied to most slow transient situations at low flow.

However, there is a possibility [9] that the critical heat flux may occur at much lower exit quality than that given above due to a change in two-phase flow regimes. In a natural circulation system with very small flow fluctuations, the occurrences of CHF have been observed at the transition between the churn-turbulent to annular flows. Beyond this transition, the lack of large disturbance waves eliminated the preexisting rewetting of dry patches. This leads to the formation of permanent dry patches and CHF. The criteria deveroped by Mishima and Ishii [9] for this case is given by

$$
q_{c}^{\prime \prime}=\frac{d_{0}}{4 l_{0}}\left\{\left(\frac{1}{C_{0}}-1\right) \Delta H_{f g} \sqrt{\rho_{g}^{\Delta \rho g d_{0}}}+G \Delta H_{\text {sub }}\right\} \text {. }
$$

Here $C_{0}$ is the distribution parameter for the drift-flux model [7] and given by

$$
c_{0}=1.2-0.2 \sqrt{\rho_{g} / \rho} \text {. }
$$

These CHF criteria should be used to develop a similarity criterion for the fluid-solid boundary instead of the heat transfer coefficient. This ensures that the critical heat flux occurs under the similar condition in a simulated system.

\section{B. Steady State Formulation for Two-phase Flow}

As has been shown in the case of a single phase flow, the steady-state solutions are very important in obtaining scales for thermo-hydraulic parameters. Therefore, a brief summary of a steady-state formulation is presented below. 
By assuming an axially uniform heat flux for simplicity of the analysis, the nonboiling length $\ell_{n b}$ of the heated section is given by

$$
l_{n b}=\frac{\Delta H_{s u b} \rho u_{0} d_{0}}{4 q_{0}^{\prime \prime}} .
$$

However, in steady-state the heat flux is related to the heat generation rate by

$$
q_{0}^{\prime \prime}=\delta \dot{q}_{s o} \text {. }
$$

The vapor quality at the exit of the heated section is given by

$$
x_{e}=\frac{4 q_{0}^{\prime \prime} l_{0}}{\rho u_{0} \Delta H_{f g}^{d}}-\frac{\Delta H_{s u b}}{\Delta H_{f g}}
$$

and the volumetric flux in the heated section by

$$
j=\left(1+\Delta \rho x / \rho_{g}\right) u_{0} .
$$

The pressure drop in the heated section can be given approximately by

$$
\begin{aligned}
\Delta p_{0} & \simeq \rho u_{0}^{2}\left\{k_{i n}+\frac{f l_{n b}}{2 d_{0}}+\frac{f}{2 d_{0}}\left[\frac{1+\frac{\Delta \rho}{\rho_{g}} \frac{x_{e}}{2}}{\left(1+\frac{\Delta \mu}{\mu_{g}} \frac{x_{e}}{2}\right)^{0.25}}\right]\left(l_{0}-l_{n b}\right)\right. \\
& \left.+\left[\frac{x_{e}^{2}}{\alpha_{e}} \frac{\rho}{\rho_{g}}+\frac{\left(1-x_{e}\right)^{2}}{\left(1-\alpha_{e}\right)}-1\right]+k_{e}\left(1+\frac{\Delta \rho}{\rho_{g}} x_{e}^{1.5}\right)\right\} \\
& +g_{\rho_{0} l_{0}}-\Delta \rho g\left[\langle\alpha\rangle_{0}\left(l_{0}-l_{n b}\right)\right] .
\end{aligned}
$$

Here the homogeneous two-phase friction factor model and outlet orifice pressure drop model have been used [18]. Furthermore, the average quality have been used for calculating the pressure drop along the heated section. Hence the mean void fraction is given approximately by 


$$
\langle\alpha\rangle_{0}=f\left(\frac{x_{e}}{2}\right)
$$

A similar pressure drop equation can be written for the other two-phase sections, i.e., the upper plenum and condensation section. From this formulation, it is clear that the density ratio, viscosity ratio, exit quality, and void-quality (or drift velocity) correlations are very important for the similarity of two-phase systems in addition to the similarity conditions for single phase flow. In essence, the exit quality corresponds to the temperature rise $\Delta T$ in a single phase flow. Furthermore, the frictional, convective, and gravitational pressure drops depend strongly on the exit quality, property ratios and void-quality correlation. These dependencies make the similarity requirement for two-phase flow much more severe than that for single phase flow.

For a natural circulation system, the total driving force can be written as

$$
\Delta p_{d r}=\beta g \rho \Delta T\left(\frac{{ }^{\ell} n}{2}+\frac{\ell_{n c}}{2}\right)+\sum_{T P}(\Delta \rho g<\alpha>\ell)_{i} \text {. }
$$

On the other hand, the resistance to the flow is given by

$$
\begin{aligned}
\Delta p_{f r} & =\frac{\rho u_{0}^{2}}{2}\left\{\sum_{S P}\left(\frac{f \ell}{d}+k\right) i\left(\frac{a_{0}}{a_{i}}\right)^{2}\right. \\
& +\sum_{T P}\left(\frac{f \ell}{d}\right)_{i}\left[\frac{1+\Delta \rho x / \rho_{g}}{\left(1+\Delta \mu x / \mu_{g}\right)^{0.25}}\right]_{i}\left(\frac{a_{0}}{a_{i}}\right)^{2} \\
& \left.+\sum_{T P} k_{i}\left(1+\Delta \rho x^{1.5 / \rho_{g}}\right)_{i}\left(\frac{a_{0}}{a_{i}}\right)^{2}\right\} .
\end{aligned}
$$

Here SP and TP denote the single phase and two-phase regions. The net convective acceleration term has been neglected because the large part of it should cancel out between the boiling and condensation processes. The right hand side of Eq. (83) represents the single phase and two-phase driving force due 
to density change. In two-phase flow, the second term should dominate because the density change by boiling is very large. It is evident from the above two expressions that reference velocity $u_{0}$ can be obtained from the solution for the quality given by Eq. (79) and the force balance. However, since this involves a void-quality correlation, it is not straight forward as in the case of single phase flow.

\section{Similarity Criteria for Two-phase Flow}

The similarity groups for two-phase flow can be obtained from the set of balance equations directly [4] or from the perturbation analysis [3]. The results obtained from the latter method are summarized below.

Phase Change No. $N_{p c h}=\frac{4 q_{0}^{\prime \prime} \ell_{0}}{d u_{0} \Delta H_{f g}{ }^{\rho}} \frac{\Delta \rho}{\rho_{g}}=\frac{\text { Flux due to Phase Change }}{\text { Injet Flux }}$

Subcooling No. $\quad N_{\text {sub }}=\frac{\Delta H_{\text {sub }}}{\Delta H_{f g}} \frac{\Delta \rho}{\rho_{g}}=\frac{\text { Subcooling }}{\text { Latent Heat }}$

Froude No. $\quad N_{F r}=\frac{u_{0}^{2}}{g l_{0}\langle\alpha\rangle_{0}} \frac{\Delta \rho}{\rho}=\frac{\text { Inertia }}{\text { Gravity Force }}$

Drift Flux No. $\quad N_{d}=\frac{v_{g j}}{u_{0}}$ (or Void Quality Relation)

Density Ratio $\quad \mathrm{N}_{\rho}=\rho_{\mathrm{g}} / \rho$

Friction No. $\quad N_{f}=\frac{f \ell}{d}\left[\frac{1+\Delta p x / \rho_{g}}{\left(1+\Delta \mu x / \mu_{g}\right)^{0.25}}\right]\left(\frac{a_{0}}{a_{i}}\right)^{2}$

Orifice No. $\quad N_{0}=K\left(1+\Delta p x^{1.5 / \rho_{g}}\right)\left(\frac{a_{0}}{a_{i}}\right)^{2}$.

In addition to the above, the single phase similarity groups given in Eq. (12) can be obtained. In case of a two-phase natural circulation, the temperature rise can be replaced by subcooling as 


$$
\Delta T_{0}=\frac{\Delta H_{\text {sub }}}{C_{p}} \text {. }
$$

In view of Eqs. (12), (85), and (86), the additional groups are

Time Ratio

$$
T_{i}^{*}=\left(\frac{\alpha_{s}}{\delta^{2}} \frac{l_{0}}{u_{0}}\right)_{i}
$$

Heat Source No. $\quad Q_{s i}=\left(\frac{\dot{q}_{s} l_{0} C_{p}}{\rho_{s} C_{p s} u_{0} \Delta H_{s u b}}\right)$

The groups related to the thermal boundary layer should be replaced by the one based on the critical heat flux. Thus

$$
\text { CHF No. } \quad \mathrm{N}_{\mathrm{q}}=\frac{\mathrm{q}_{\mathrm{c}}^{\prime \prime}}{\mathrm{q}_{0}^{11}}
$$

where $q_{c}^{\prime \prime}$ is given by Eqs. (73), (74) or (75) depending on the CHF mechanisms. In view of Eqs. (78) and (85), the phase change number can be modified to

$$
N_{p c h}=\frac{4 \delta \dot{q}_{o} \ell_{0}}{d u_{0} \Delta H_{f g} \rho} \frac{\Delta \rho}{\rho_{g}} .
$$

On the other hand, the relative velocity scale based on the drift velocity correlation is

$$
N_{d}=0.2\left(1-\sqrt{\rho_{g} / \rho}\right)\left(1+\Delta \rho x / \rho_{g}\right)+\frac{1.41}{u_{0}}\left(\frac{\sigma g \Delta \rho}{\rho^{2}}\right)^{1 / 4}
$$

or it should have the same void quality correlation

$$
\alpha=f\left(x, \rho_{g} / \rho, \mu_{g} / \mu, \text { etc. }\right) \text {. }
$$

The original similarity parameters and the modified ones given above indicate that the similarity criteria for different fluids at different pressures are extremely complicated. However, if the following conditions are met, significant simplifications can be made. 
Negligible Effects of Viscosity Ratio on Two-phase Friction

Relatively Small Exit Orificing

Relatively Small Local Slip

In general, it can be shown from Eqs. (79) and (85),

$$
\Delta \rho X_{e} / \rho_{g}=\left(N_{p c h}-N_{s u b}\right)
$$

Therefore, the similarity based on the phase change number and subcooling number can satisfy $N_{d}, N_{f}$, and $N_{0}$ approximately. For a natural circulation the Froude number and thus the void fraction plays a very important roll at the low quality. However, at relatively high quality, the void fraction is very close to unity and, therefore, the driving force becomes only dependent on the length of the two-phase region.

Physically, the phase change number is the scale for the amount of heating and phase change, whereas the subcooling number is the scale for the cooling in the condensation section. The subcooled liquid temperature is mainly determined by the excess cooling in this section. The similarity analysis becomes much more complicated when there is not sufficient cooling to condense all of the steam or the subcooling cannot be well controlled by the condensation section. In such a case, detailed modeling of condensation process and the analysis of the secondary loop may become necessary to determine the exit quality or subcooling at the condensation section.

\section{Scale Model with Same Fluid}

A special case of a scale model with same fluid under same pressure is now examined because of $i$ ts obvious importance. In this case, all the fluid properties can be considered the same between the model and prototype, thus

$$
\rho_{R}=\rho_{g R}=B_{R}=C_{p R}=k_{R}=\mu_{R}=\mu_{g R}=\Delta H_{f g R}=1 .
$$

Under the above condition, the similarity criteria become

$$
\begin{aligned}
& \left(N_{\text {pch }}\right)_{R}=\frac{\delta_{R} q_{R} R_{R}}{d_{R} u_{R}}=1 . \\
& \left(N_{\text {sub }}\right)_{R}=\left(\Delta H_{\text {sub }}\right)_{R}=1 .
\end{aligned}
$$




$$
\begin{aligned}
& \left(N_{F r}\right)_{R}=\frac{u_{R}^{2}}{\ell_{R}^{\langle\alpha\rangle_{R}}}=1 . \\
& \left(N_{f}\right)_{R}=\left(\frac{f \ell}{d}\right)_{R}\left(\frac{a_{0}}{a_{i}}\right)_{R}^{2}=1 . \\
& \left(N_{0}\right)_{R}=K_{R}\left(\frac{a_{0}}{a_{i}}\right)_{R}^{2}=1 .
\end{aligned}
$$

The drift flux number can be automatically satisfied, if the contribution of the local slip is small in comparison with the slip due to the transverse velocity and void profiles. When the local slip, i.e., the second term on R.H.S. of Eq. (90), is the dominant factor for the relative motion, the similarity requirement is $u_{R}=1$ which is a rather severe restriction. Hence from $\left(N_{d}\right)_{R}=1$ one obtains,

$$
\left\{\begin{array}{l}
\text { Distribution Controlled Slip } \rightarrow \text { Automatically Satisfied } \\
\text { Local Slip Controlled } \rightarrow u_{R}=1
\end{array} .\right.
$$

For most cases the first condition applies. Even in the second case, the distortion of the velocity will introduce limited changes in the void-quality relation. Therefore, in the following analysis the first condition will be assumed.

From Eqs. (92) to (93), it is evident that basically the similarity in terms of the vapor quality is satisfied. Thus

$$
x_{R}=1
$$

And from Eq. (99) this implies that the void similarity also exists,

$$
a_{\mathrm{R}}=1 \text {. }
$$

Hence, excluding the friction similarity conditions, it is required that 


$$
\begin{aligned}
& \frac{\delta_{R}}{d_{R}} \frac{q_{R} l_{R}}{u_{R}}=1 \\
& \left(\Delta H_{s u b}\right)_{R}=1 . \\
& u_{R}^{2} / l_{R}=1
\end{aligned}
$$

In addition to the above, the critical heat flux similarity requires

$$
\left(\frac{q_{C}^{\prime \prime}}{q^{\prime \prime}}\right)_{R}=1
$$

Using the Katto CHF criterion given by Eq. (74) and $N_{p c h}$ similarity criteria, it can be shown that Eq. (103) becomes

$$
\left(x_{C}\right)_{R}=\left(\frac{1}{u_{R}^{2} R^{\prime}}\right)^{0.043}=1 .
$$

It is noted that the exponent of the above expression is very small at 0.043 . This implies that the $x_{c}$ is in the range of $0.6 \sim 0.8$. Therefore, it may safely be assumed that Eq. (104) is approximately satisfied if the quality similarity given by Eq. (100) holds.

From the single phase scaling criteria on geometry given by Eqs. (44) and (45), it is necessary that

$$
u_{R}=\sqrt{\ell_{R}}
$$

and

$$
q_{R}=\frac{1}{\sqrt{\ell_{R}}}
$$

These requirements also satisfy the single phase scaling criteria on the velocity given by $\mathrm{Eq}$. (43). However, the real time simulation cannot be achieved in case of two-phase flow due to the additional conditions imposed on the system. Furthermore, Eq. (105) implies that the power to the system should be increased in a model. Additional caution should be paid to the simulation of 
the CHF under natural circulation conditions. For example, if the CHF occurs due to the local condition such as given by Eq. (73), it cannot be simulated by the above scaling criteria.

\section{E. Sample Calculations}

As an example, a preliminary consideration on the simulation of LWR by the LOFT facility is presented. In this case, as stated above it is not possible to operate in the real time scale. Therefore, the time scale should be distorted in order to have a meaningful simulation.

From Eqs. (60) and (105)

$$
\begin{aligned}
& l_{R}=0.4 \sim 0.44 \\
& u_{R}=0.63 \sim 0.66 . \\
& q_{R}=1.58 \sim 1.51
\end{aligned}
$$

The geometrical similarity criteria given by Eqs. (44) and (45) requires that

$$
\delta_{\mathrm{R}}=\mathrm{d}_{\mathrm{R}} \stackrel{\bullet}{=} 0.8 \text {. }
$$

The subcooling or the secondary loop temperature is limited by

$$
\left(\Delta H_{S u b}\right)_{R}=1
$$

Furthermore, for an accurate simulation, it is necessary that in two-phase sections the friction and orifice number satisfy

$$
\left(\frac{f \ell}{d}\right)_{R}=1 \quad \text { or } \quad f_{R}=2 \sim 1.8
$$

and

$$
K_{R}=1
$$

where it was assumed that $\left(a_{i} / a_{0}\right)_{R}=1$ based on $d_{R}=$ constant. On the other hand, for single phase sections the overall friction similarity is sufficient. 
It is noted that the above conditions also satisfies the single phase natural circulation requirements. The exception is the simulation of the turbulent boundary layer. As mentioned above the time scale is distorted by

$$
t_{R} \doteq \frac{\ell_{R}}{u_{R}}=0.63 \sim 0.66
$$

Therefore, the time events will be accelerated in the model.

The above similarity requirement can be compared to the parameters given in Table I. It is clear that the geometrical condition given by Eq. (107) is only met approximately. Furthermore, Eq. (106) shows that the power should be higher in the LOFT facility by $50 \%$ or more. It is necessary to adjust the frictional pressure drop coefficients by installing several orifices in the two-phase flow sections. For modifications of the facility or designing experiments, much more detailed analysis may be needed. In the present analys is only the general similarity criteria and the feasibility of using the LOFT facility are examined.

\section{SUMMARY AND CONCLUSIONS}

Scaling criteria for a natural circulation loop under single phase and two-phase flow conditions have been derived from the fluid balance equations, boundary conditions, and solid energy equations. For a single phase case the continuity, integral momentum, and energy equations in one-dimensional area averaged forms have been used. The solid heat conduction is considered only in a direction normal to the flow, therefore, the effect of axial conduction has been neglected. For a two-phase natural convection case the one-dimensional drift-flux model obtained from the short time temporal averaging the sectional area averaging has been used.

The set of balance equations and boundary conditions is nondimensionalized by using reference scales and steady state solutions. From this, important similarity groups have been identified. The natural circulation in a closed loop is induced by the density changes due to heating up of liquid and due to boiling. Therefore, special attention has been paid to the driving head of the gravitational term in the differential and integral momentum equations. The coupling of this gravitational driving force with the solution of the fluid energy equation is the particular characteristic of a natural circulation loop. 
The above similarity analysis shows that for a single phase case the geometrical similarity group, friction number, Richardson number, characteristic time constant ratio, Biot number, and heat source number are important. It can be shown that the Stanton number, obtainable from the fluid energy equation, is redundant in terms of the above similarity groups. The geometrical similarity group consists of the axial length and flow area ratio of various sections. The Biot number involves the constitutive relation for the heat transfer coefficient. This will cause some difficulties in case of a fluid to fluid simulation, however, the relaxation of the Biot number similarity condition influences the boundary layer temperature drop only, and, therefore, it may not be very significant in the single phase case.

In the case of two-phase natural circulation, the dimensional analysis shows that the phase change number, drift-flux number, friction number, density ratio, and two-phase Froude number are the important similarity groups. The physical significances and conditions imposed by these similarity parameters are discussed. These are interpreted into the conditions on the operational parameters and standard two-phase flow parameters such as the void fraction and quality. In the two-phase case, the critical heat flux is one of the important transients which should be simulated in a scale model. This additional condition is also discussed in detail in terms of the standard high quality CHF and the newly discovered low quality CHF.

The above results are applied to the LOFT facility in case of a natural circulation simulation. The fluid and pressure levels are assumed to be the same between the model and prototype. Therefore, the similarity criteria are evaluated with respect to the operational conditions and system geometry. In particular, the feasibility of the real time simulation which imposes an additional constraint is discussed. The results show that the real time simulation is only possible in the case of a single phase flow. The similarity criteria for two-phase natural circulation basically requires the similarity in terms of the steam quality and void fraction. Because of this, the power requirement for a scale model should be considerably higher than in the prototype. The detailed geometrical similarity in the two-phase region is quite important due to the strong dependence of the frictional and gravitational pressure drops on the steam quality or void fraction. It appears that some modification of the LOFT facility by installing several orifices in the hot legs is necessary. 
In the present study, only general similarity criteria and the feasibility of using the LOFT facility for PWR natural circulation simulations have been examined. A more detailed study may be necessary for optimum modifications of the facility or designing experimental programs. 


\section{ACKNOWLEDGMENTS}

This work was performed under the auspices of the U. S. Nuclear Regulatory Commission. 


\section{REFERENCES}

1. M. P. Heisler and R. M. Singer, "Facility Requirements for Natural Convection Shutdown Heat Removal System Testing," Decay Heat Removal and Natural Convection in Fast Breeder Reactors, Hemisphere, p. 113 (1981).

2. M. P. Heisler, "Development of Scaling Requirements for Natural Convection Liquid-Metal Fast Breeder Reactor Shutdown Heat Removal Test Facilities," Nuc1. Sci. Eng. 80, p. 347 (1982).

3. M. Ishii and N. Zuber, "Thermally Induced Flow Instabilities in Twophase Mixtures," 4th Int. Heat Trans. Conf., Paris, paper B5.11 (1970).

4. M. Ishii and 0. C. Jones, Jr., "Derivation and Application of Scaling Criteria for Two-phase Flows," Two-phase Flows and Heat Transfer, Proc. NATO Advanced Study Institute, Istanbu1, Turkey, Vol. 1, p. 163 (1976).

5. N. Zuber, "Problems in Modeling of Sma11 Break LOCA," NRC NUREG-0724 Report (1980).

6. N. Zuber and J. A. Findlay, "Average Volumetric Concentration in Twophase Flow Systems," J. Heat Trans. 87, p. 453 (1965).

7. M. Ishii, "One-dimensional Drift-flux Model and Constitutive Equations for Relative Motion between Phases in Various Two-phase Flow Regimes," Argonne Report ANL-77-47 (1977).

8. D. L. Reeder, "LOFT System and Test Description," NUREG/CR-0247, TREE1208 (1978).

9. K. Mishima and M. Ishii, "Critical Heat Flux Experiments under Low Flow Conditions in a Vertical Annulus," NUREG/CR-2647, ANL-82-6 (1982).

10. M. Ishii, "Thermo-fluid Dynamic Theory of Two-phase Flow," Eyrolles, Paris (1975).

11. M. Ishii and N. Zuber, "Drag Coefficient and Relative Velocity in Bubbly, Droplet or Particulate Flows," AIChE J. 25, p. 843 (1979).

12. M. Ishii, "Foundation of Various Two-phase Flow Models and Their Limitations," NRC-EPRI Joint Conf. on Simulation Methods for Nuclear Power Systems, EPRI WS-81-212, p. 3-47 ( 81).

13. L. S. Tong, "Boiling Heat Transfer and Two-phase Flow," R. E. Krieger, NY $(1975)$.

14. Y. Y. Hsu and R. W. Graham, "Transport Processes in Boiling and Two-phase Systems," Hemisphere, WA (1976).

15. J. C. M. Leung, "Occurrence of Critical Heat Flux during Blowdown with Flow Reversal," ANL-77-4 (1977). 
16. Y. Katto, "A Generalized Correlation of Critical Heat Flux for Forced Convection Boiling in Vertical Uniformly Heated Round Tube," Int. J. Heat Mass Trans., Vol. 21, p. 1527 (1978).

17. P. Griffith, J. F. Pearson, and R. J. Lepkowski, "Critical Heat Flux During a Loss-of-Coolant Accident," Nucl. Saf. 18(3), p. 298 (1977).

18. J. G. Collier, "Convective Boiling and Condensation," McGraw-Hi11, NY (1972). 
Internal:
E. S. Beckjord
D. H. Cho
P. B. Abramson
W. L. Chen
C. E. Till
B. W. Spencer
R. Avery
W. A. Ragland
J. F. Marchaterre
G. De Jarlais
A. J. Goldman
D. P. Weber
P. A. Lottes
W. T. Sha
D. Rose
Y. W. Shin
D. M. France
T. C. Chawla
H. U. Wider
M. Ishii (20)
ANL Patent Dept.
ANL Contract File
ANL Libraries (2)
TIS Files (6)

\section{External:}

NRC Washington, for distribution per R2 and R4 (395)

DOE-TIC (2)

Manager, Chicago Operations Office, DOE

Reactor Analysis and Safety Division Review Committee:

W. P. Chernock, Combustion Engineering, Inc., 1000 Prospect Hill Road, Windsor, Conn. 06095

L. C. Hebel, Xerox Corp., 3333 Coyote Hill Road, Palo Alto, Calif. 94304

S. Levine, NUS Corp., 910 Clopper, Gaithersburg, Md. 20878

W. F. Miller, Jr., Los Alamos National Laboratory, Los Alamos, N. M. 87545

M. J. Ohanian, University of Florida, Gainesville, Fla. 32611

T. H. Pigford, University of Cal ifornia, Berkeley, Cal if. 94720

J. J. Taylor, Electric Power Research Inst., P. 0. Box 10412, Palo Alto, Cal if. 94303 
